Original Article

\title{
Evaluation of muscle damage using ultrasound imaging
}

\author{
JAe-Young Yu, PhDc, PT ${ }^{1)}$, Jin-Gyu Jeong, PhD, PT ${ }^{2 *}$, Byung-Hun Lee, PhD, PT ${ }^{3)}$ \\ 1) Department of Physical Therapy, Graduate School of Dongshin University, Republic of Korea \\ 2) Department of Physical Therapy, Chunnam Techno University: 113 Daehak-ro, Okgwa-myeon, \\ Gokseong-gun, Jeollanam-do 516-911, Republic of Korea \\ 3) Group of Industry-Academy Cooperation, Chunnam Techno University, Republic of Korea
}

\begin{abstract}
Purpose] This study aimed to quantitatively analyze characteristics of and changes in internal muscle structure according to the time of delayed onset muscle soreness (DOMS) using ultrasound imaging, thereby presenting clinical evidential data for evaluation of muscle damage. [Subjects] We recruited 38 male subjects. [Methods] Ultrasound images of the medial gastrocnemius muscle prior to induction of DOMS and immediately after, 24 hours after, 48 hours after, and 72 hours after induction of DOMS were obtained, and the thickness and pennation angle of the muscle were measured. [Results] The muscle thickness gradually increased until 48 hours after induction of DOMS and decreased after 72 hours. The pennation angle also gradually increased until 48 hours after induction of DOMS and decreased after 72 hours. [Conclusion] Ultrasound imaging is considered useful for assessment of structural characteristics of muscles when muscle damage like DOMS takes place.

Key words: DOMS, Muscle thickness, Pennation angle
\end{abstract}

(This article was submitted Aug. 12, 2014, and was accepted Sep. 10, 2014)

\section{INTRODUCTION}

Delayed onset muscle soreness (DOMS) is triggered by exercises to which one is not accustomed ${ }^{1)}$. Its symptoms start to appear between 8 and 20 hours after the damage and reach their peak between 24 and 48 hours after the damage $^{2-4)}$. DOMS decreases movement ability and causes discomfort in ordinary life ${ }^{5}$.

Repetitive muscle contraction like DOMS over a long period results in microdamage to fast twitch muscle fibers and is accompanied by pain, increased muscle tone, local edema, a burning sensation, reduced range of motion, decreased muscle strength, and muscle fatigue ${ }^{6}$. Temporary muscle damage, including DOMS, is not a severe condition, but when pain and muscle spasticity are serious, appropriate treatment is required ${ }^{7}$. When an overload of exercise is sustained under a condition of weakened muscles, permanent muscle damage is likely to be induced ${ }^{8)}$. Therefore, research aimed at diagnosing muscle damage and verifying treatment effects is ongoing.

A lot of research has been conducted to examine muscle fiber size, thickness, and shape and structural characteristics of the muscles ${ }^{9)}$; at present, structural traits of the muscles

*Corresponding author. Jin-Gyu Jeong (E-mail: ptj8763@ hanmail.net)

C2015 The Society of Physical Therapy Science. Published by IPEC Inc. This is an open-access article distributed under the terms of the Creative Commons Attribution Non-Commercial No Derivatives (by-ncnd) License $<$ http://creativecommons.org/licenses/by-nc-nd/3.0/> . are evaluated using ultrasound imaging, magnetic resonance imaging (MRI), and computed tomography (CT) as science and technology and state-of-the-art equipment advance.

Ultrasound imaging is known to be a reliable method of measuring the cross-sectional area and volume of the muscles and is applied to analyze skeletal muscle adaptation to muscle strengthening programs ${ }^{10}$. Ultrasound imaging analysis is inexpensive compared with other diagnostic imaging tests like CT and MRI, is noninvasive, and is simple to use, and it does not pose the risk of $\mathrm{x}$-ray exposure ${ }^{11)}$. Moreover, muscle function and thickness, pennation angle, and fascicle length, which are structural characteristics of the muscles, may be measured and analyzed through ultrasound imaging ${ }^{12-14)}$

Diverse evaluation tools are used to assess DOMS, including muscle strength measurement devices, electromyography, and the algometer, but most assessment tools deal with only the functional parts of the muscles. There is a lack of research identifying structural changes in the muscles through digital imaging analysis. Therefore, this study aimed to provide clinical evidential data for the evaluation of muscle damage by quantitatively analyzing characteristics of and changes in the internal structure of skeletal muscles after induction of DOMS.

\section{SUBJECTS AND METHODS}

The researchers obtained approval from the Clinical Study Ethics Committee of Chunnam Techno University (1041557-201403-HR-001-02), recruited male students at the university, and explained the purpose and procedure 
of this experiment to them. The subjects were confined to those who voluntarily provided a written agreement to participate in this experiment. Forty healthy male students were selected as the subjects of this study, and specific criteria for inclusion were as follows: the participants had no history of diseases related to the legs, had no diseases or pain restricting exercise, and had not performed sports activities in the last two weeks. The number of final subjects was 38 , as two students elected to drop out. The general characteristics of the subjects are shown in Table 1.

In order to induce DOMS in the subjects, the researcher instructed them to slowly raise the heel of the nondominant leg, maximally contracting the calf muscle, on a $35^{\circ}$ slant plate devised by the researcher, and then to put down the heel slowly, feeling resistance, until the sole touched the plane of the plate. The motion was carried out 50 times per set, and the subjects carried out two sets. The resting time between sets was 30 seconds $^{15}$ ). In order to more effectively induce DOMS, the researcher applied a shorter resting time than in previous research. Measurements were taken a total of five times - prior to induction of DOMS and immediately after, 24 hours after, 48 hours after, and 72 hours after induction of DOMS.

The structure of the left medial gastrocnemius muscle was measured using an ultrasound imaging device (MyLabOne, Esaote, Italy). The frequency modulation range was $10 \mathrm{MHz}$, and as an ultrasonic transducer, a 7.5 MHz linear transducer was used. For muscle measurement, the subjects lay in a prone position and maintained complete extension of the knee joints. While the subjects relaxed, measurements were made longitudinally in parallel with the direction of the medial belly grain of the gastrocnemius muscle at the location of one-third of the length from the center of the knee joint to the calcaneus toward the body. Measurements were made after marking the measured area with a surgical pen in order to precisely maintain the area. To minimize pressure on the skin, a sufficient amount of ultrasound gel (Care Sonic, Seoul, South Korea) was applied between the transducer and the skin, and images were obtained by maintaining the transducer vertical to the skin for constant measurement.

The distance between the superior aponeurosis and the inferior aponeurosis was measured three times so as not to include the aponeurosis in the muscle thickness (Fig. 1). The average values were used for analysis.

In order to measure the pennation angle, the fascicles located between the superior aponeurosis and the inferior aponeurosis of the gastrocnemius muscle were extracted from ultrasound images and identified using Image-Pro Plus 4.5 (Media Cybernetics, Rockville, MD, USA), and the angle between the inferior aponeurosis and the fascicles was measured (Fig. 2).

The collected data were analyzed using PASW ver. 18.0 for Windows. The measured data were derived as average values and standard deviations. In order to examine changes in the muscle thickness and pennation angle over time, one-way analysis of variance was employed, and Tukey's multiple range test was conducted as a post hoc test. The significance level was set at $\alpha=0.05$ in order to verify statistical significance.
Table 1. Common characteristics of the subjects $(\mathrm{N}=38$, mean $\pm \mathrm{SD})$

\begin{tabular}{ccc}
\hline Age $(\mathrm{yr})$ & Height $(\mathrm{cm})$ & Weight $(\mathrm{kg})$ \\
\hline $24.9 \pm 2.9$ & $175.6 \pm 5.0$ & $69.9 \pm 6.4$ \\
\hline
\end{tabular}

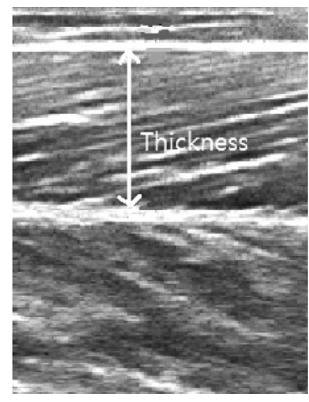

Fig. 1. Muscle thickness of medial gastrocnemius

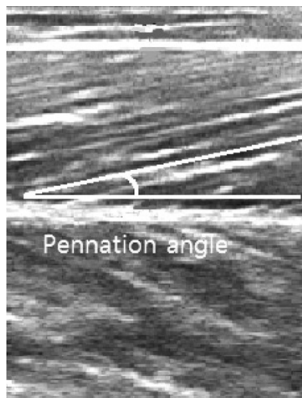

Fig. 2. Pennation angle of medial gastrocnemius

\section{RESULTS}

Muscle thickness was statistically significantly different among prior to, immediately after, 24 hours after, 48 hours after, and 72 hours after induction of DOMS $(\mathrm{p}<0.001)$. The pennation angle was statistically significantly different among prior to, immediately after, 24 hours after, 48 hours after, and 72 hours after induction of DOMS $(p<0.001)$ (Table 2).

\section{DISCUSSION}

DOMS is a physical symptom experienced when muscles that are ordinarily not used are utilized excessively, and is completely recoverable within 5 to 7 days after its onset. Therefore, it is not considered a severe trauma. Nonetheless, DOMS may greatly impede ordinary life and performance of exercise for health; moreover, if the area of pain is not well managed, it may lead to a serious injury.

Eccentric contraction that forcibly increases the length of muscles and generates tensile force overextends the normal sarcomeres and triggers microdamage to them, resulting in damage to the muscle cell membranes. Such damage causes local muscle shortening, and when this is severe, muscle cell 
Table 2. Muscle thickness and pennation angle changes according to the passage of time (mean $\pm \mathrm{SD}$ )

\begin{tabular}{lllcccc}
\hline & Pre $^{\mathrm{a})}$ & Post $^{\mathrm{b})}$ & ${\left.\text { After } 24 \mathrm{~h}^{\mathrm{c}}\right)}$ & ${\text { After } 48 \mathrm{~h}^{\mathrm{d})}}$ & ${\text { After } 72 \mathrm{~h}^{\mathrm{e})}}$ & Post hoc \\
\hline MT $(\mathrm{cm})$ & $1.60 \pm 0.23$ & $1.75 \pm 0.25$ & $1.80 \pm 0.24$ & $1.88 \pm 0.26$ & $1.84 \pm 0.29$ & a:c,d,e \\
PA $\left(^{\circ}\right)$ & $20.9 \pm 4.6$ & $21.5 \pm 4.1$ & $24.8 \pm 5.0$ & $26.8 \pm 5.7$ & $25.5 \pm 4.7$ & a:c,d,e \\
& & & & & & \\
\hline
\end{tabular}

MT: muscle thickness, PA: pennation angle

necrosis may arise. Consequently, the tensile force of the muscle is decreased, and inflammation and edema occur ${ }^{16)}$.

Normal muscles become thicker, their muscle fibers are shortened, and their pennation angles become larger when they contract compared with when they are at rest ${ }^{17)}$. However, damaged muscles necessarily exhibit mechanical property changes, which are closely related to changes in their internal structures, including fascicle length, pennation angle, and muscle thickness ${ }^{18)}$

Ultrasound imaging equipment that measures such structural changes in the muscles is known to facilitate integrated analysis via noninvasive, structural, quantitative, and qualitative evaluation of the muscles ${ }^{19}$ ). It also allows muscle shape and structure to be visualized, and the muscles to be quantified ${ }^{11)}$.

The pennation angle refers to a direction angle between muscle fibers and tendons. A muscle whose pennation angle is $0^{\circ}$ delivers $100 \%$ of contractility to the tendons, while a muscle with a pennation angle of $30^{\circ}$ sends only $86 \%$ of its contractility to the tendons. The pennation angle of most human muscles ranges from 0 to $30^{\circ 20}$ ). Reeves et al. ${ }^{21)}$ reported that a structural change in skeletal muscle relating to parameters such as the pennation angle and fascicle length occurred according to changes in muscle strength, and Fukunaga et al. ${ }^{22)}$ noted that the pennation angle was fairly important in determining functional characteristics of the muscles and was associated with force generation in the muscle-tendon complex.

Existing research on ultrasound imaging has mostly dealt with changes in the internal structure of the muscles during maximal voluntary isometric contraction, but such an approach may trigger personal and rater errors. Therefore, in order to precisely measure ultrasound images, the present study focused on the internal structure of the muscles during relaxation, not during contraction. Thus, this study identified whether there were changes in the internal structure of the muscles according to muscle damage during relaxation, attempting to provide clinical evidential data for muscle damage evaluation.

According to the results, the muscle thickness and pennation angle over time after the induction of DOMS statistically significantly increased relative to prior to the experiment. They gradually increased from right after induction to 48 hours after induction and then decreased. Nosaka and Clarkson $^{23)}$ measured muscle thickness using ultrasound imaging in order to look at changes in the muscular edema caused by DOMS after eccentric contraction exercise and reported that inflammatory edema and protein synthesis resulted in edema 2 days after the induction of DOMS and connective tissue proliferation 3 to 4 days after induction, with a great increase in the muscle thickness. Sbriccoli et al. ${ }^{4}$ induced
DOMS through eccentric contraction and measured changes in muscle thickness using ultrasound imaging; the muscle thickness started to increase immediately after the induction of DOMS, grew by about $17 \%$ two days after induction, and then gradually recovered, which was similar to the present study results. This probably occurred because muscle damage increased muscle tone and muscular edema, thereby augmenting the thickness of the muscles. Arampatzis et al. ${ }^{24)}$ noted that the pennation angle became considerably larger during maximal voluntary isometric contraction compared with during relaxation. Moreover, Nagayoshi et al. ${ }^{25}$ ) observed that there was significant correlation between the pennation angle and maximal voluntary isometric contraction. Maganaris et al. ${ }^{26)}$ reported that structural characteristics of the muscles changed considerably during maximal voluntary isometric contraction, showing that muscle contractility and the pennation angle were closely related. In addition, Lieber and Friden ${ }^{20)}$ noted that the more muscle contractility decreased, the more the pennation angle increased, supporting the present study results.

To sum up the findings of the present study, microdamage to the sarcomeres resulting from DOMS triggers decreased muscle tensile force, inflammation, and edema, thereby increasing the thickness of muscle fibers and the pennation angle. This in turn aggravates pain and lowers muscle contractility.

The limitations of this study are as follows. First, the number of subjects in this study was small, as it was performed with only 38 male college students. Therefore, it is difficult to generalize this study result to females and those in different age ranges. Second, food intake and levels of activity of the subjects were not controlled. Third, the variable measurement interval was not minute; measurements were made at intervals of 24 hours.

Ultrasound imaging is regarded to be effective in evaluating structural muscle traits after inducing muscle damage such as DOMS. In addition to structural assessment, future research involving qualitative evaluation of imaging density and comparison of differences according to muscle contraction and relaxation after muscle damage is considered necessary.

\section{REFERENCES}

1) Kuipers H: Exercise-induced muscle damage. Int J Sports Med, 1994, 15: 132-135. [Medline] [CrossRef]

2) Ebbeling CB, Clarkson PM: Exercise-induced muscle damage and adaptation. Sports Med, 1989, 7: 207-234. [Medline] [CrossRef]

3) Kisner C, Colby LA: Therapeutic exercise: foundations and techniques, 6th ed. Philadelphia: F. A. Davis, 2012.

4) Sbriccoli P, Felici F, Rosponi A, et al.: Exercise induced muscle damage and recovery assessed by means of linear and non-linear sEMG analysis and ultrasonography. J Electromyogr Kinesiol, 2001, 11: 73-83. [Medline] 
[CrossRef]

5) Miles MP, Clarkson PM: Exercise-induced muscle pain, soreness, and cramps. J Sports Med Phys Fitness, 1994, 34: 203-216. [Medline]

6) Cleak MJ, Eston RG: Muscle soreness, swelling, stiffness and strength loss after intense eccentric exercise. Br J Sports Med, 1992, 26: 267-272. [Medline] [CrossRef]

7) MacIntyre DL, Reid WD, McKenzie DC: Delayed muscle soreness. The inflammatory response to muscle injury and its clinical implications. Sports Med, 1995, 20: 24-40. [Medline] [CrossRef]

8) Connolly DA, Sayers SP, McHugh MP: Treatment and prevention of delayed onset muscle soreness. J Strength Cond Res, 2003, 17: 197-208. [Medline]

9) Bilodeau M, Schindler-Ivens S, Williams DM, et al.: EMG frequency content changes with increasing force and during fatigue in the quadriceps femoris muscle of men and women. J Electromyogr Kinesiol, 2003, 13: 83-92. [Medline] [CrossRef]

10) Sipilä S, Suominen H: Quantitative ultrasonography of muscle: detection of adaptations to training in elderly women. Arch Phys Med Rehabil, 1996 77: 1173-1178. [Medline] [CrossRef]

11) Chi-Fishman G, Hicks JE, Cintas HM, et al.: Ultrasound imaging distinguishes between normal and weak muscle. Arch Phys Med Rehabil, 2004 85: 980-986. [Medline] [CrossRef]

12) Kim TG, Bae SH, Kim GY, et al.: Analysis of ultrasonographic architectural properties of muscles of chronic stroke patients during different muscle activities. J Phys Ther Sci, 2012, 24: 1059-1062. [CrossRef]

13) Kim BI, Hwang-Bo G, Kim HR: Comparison of abdominal muscle thickness with vaginal pressure changes in healthy women. J Phys Ther Sci, 2014, 26: 427-430. [Medline] [CrossRef]

14) Kasuyama $T$, Sakamoto $M$, Kato $K$ : Comparing changes in the calf muscle during weight-bearing and non-weight-bearing stretching. J Phys Ther Sci, 2011, 23: 395-399. [CrossRef]

15) Tegeder L, Zimmermann J, Meller ST, et al.: Release of algesic substances in human experimental muscle pain. Inflamm Res, 2002, 51: 393-402.
[Medline] [CrossRef $]$

16) Proske U, Morgan DL: Muscle damage from eccentric exercise: mechanism, mechanical signs, adaptation and clinical applications. J Physiol, 2001, 537: 333-345. [Medline] [CrossRef]

17) Narici MV, Maganaris CN, Reeves ND, et al.: Effect of aging on human muscle architecture. J Appl Physiol 1985, 2003, 95: 2229-2234. [Medline]

18) Gao F, Grant TH, Roth EJ, et al.: Changes in passive mechanical properties of the gastrocnemius muscle at the muscle fascicle and joint levels in stroke survivors. Arch Phys Med Rehabil, 2009, 90: 819-826. [Medline] [CrossRef]

19) Benington PC, Gardener JE, Hunt NP: Masseter muscle volume measured using ultrasonography and its relationship with facial morphology. Eur J Orthod, 1999, 21: 659-670. [Medline] [CrossRef]

20) Lieber RL, Fridén J: Clinical significance of skeletal muscle architecture. Clin Orthop Relat Res, 2001, (383): 140-151. [Medline] [CrossRef]

21) Reeves ND, Narici MV, Maganaris CN: Effect of resistance training on skeletal muscle-specific force in elderly humans. J Appl Physiol 1985, 2004, 96: 885-892. [Medline] [CrossRef]

22) Fukunaga $T$, Kawakami $Y$, Kuno S, et al.: Muscle architecture and function in humans. J Biomech, 1997, 30: 457-463. [Medline] [CrossRef]

23) Nosaka K, Clarkson PM: Changes in indicators of inflammation after eccentric exercise of the elbow flexors. Med Sci Sports Exerc, 1996, 28: 953-961. [Medline] [CrossRef]

24) Arampatzis A, Karamanidis K, Stafilidis S, et al.: Effect of different ankle- and knee-joint positions on gastrocnemius medialis fascicle length and EMG activity during isometric plantar flexion. J Biomech, 2006, 39: 1891-1902. [Medline] [CrossRef]

25) Nagayoshi T, Kawakami Y, Maeda M, et al.: The relationships between ankle dorsiflexion torque and muscle size indices. Int J Sport Health Sci, 2003, 1: 216-221. [CrossRef]

26) Maganaris $\mathrm{CN}$, Baltzopoulos V, Sargeant AJ: In vivo measurements of the triceps surae complex architecture in man: implications for muscle function. J Physiol, 1998, 512: 603-614. [Medline] [CrossRef] 